\title{
The prevalence of hearing loss in children and adolescents with cancer
}

\author{
Aline Medeiros da Silva ', Maria do Rosário Dias \\ de Oliveira Latorre ${ }^{2}$, Lilian Maria Cristofani ${ }^{3}$, \\ Vicente Odone Filbo ${ }^{4}$
}

Keywords: childhood cancer, ototoxicity, hearing loss, chemotherapy.

\section{Summary}

\begin{abstract}
$\mathrm{T}$ he treatment of cancer in children has several side effects, including ototoxicity. Inner ear structures may be affected and hearing loss may ensue. Aim: To estimate the prevalence of hearing loss in patients with cancer using the American Speech-Language-Hearing Association (ASHA), the Pediatric Oncology Group Toxicity (POGT), and the Bilateral Hearing Loss (PAB) criteria. Study design: a prospective study. Material and Methods: 94 patients admitted between 2003 and 2004 were analyzed. Visual inspection of the external auditory meatus and an audiologic evaluation were done. Descriptive statistics was used to characterize the sample, and Kappa statistics was used to investigate concordance of hearing loss in the three types of classification. Results: The prevalence of hearing loss was 42.5\% using ASHA, 40.4\% using POGT, and $12.8 \%$ using PAB. The concordance of hearing loss was weak for POGT and PAB $(\mathrm{k}=0.36)$ and for PAB and ASHA ( $k=0.33)$. The concordance between ASHA and POGT was almost perfect $(\mathrm{k}=0.96)$. Conclusions: Hearing loss is an important side effect of the treatment of cancer in children. Periodic audiology monitoring is recommended to detect early hearing loss and to revise the treatment if necessary. Adoption of a classification system that detects mild hearing loss (ASHA) is recommended.
\end{abstract}

${ }^{1}$ M.S. Student in Public Health - USP School of Public Health. Speech and Hearing Therapist.

${ }^{2}$ Associate Professor - School of Public Health - USP, Full Professor- Department of Epidemiology - School of Public Heath - University of São Paulo (USP).

${ }^{3} \mathrm{PhD}$ in Pediatrics - University of São Paulo Medical School. Assistant Physician - Department of Pediatric Cancer - ITACI. University of São Paulo Hospital. ${ }_{4}^{4}$ Associate Professor - USP Medical School. Head of the Pediatric Cancer Institute- ITACI. University of São Paulo Hospital. School of Public Health - University of São Paulo (USP).

Send correspondence to: Aline Medeiros da Silva - Avenida Dr. Arnaldo 715 Departamento de Epidemiologia FSP/USP 01246-904 São Paulo SP. Tel. (0xx11) 3061-7744 (0xx11) 8365-3966 - E-mail: alinems@usp.br

FAPESP - Fundaç̃o de Amparo a Pesquisa do Estado de São Paulo.

Paper submitted to the ABORL-CCF SGP (Management Publications System) on June 26th, 2006 and accepted for publication on October 12th, 2006. cod. 2247. 


\section{INTRODUCTION}

The increase in survival rates of children and adolescents with malignant tumors in the last two decades reflects more effective treatments - including combined chemotherapy, better diagnostics, better surgical techniques and radiotherapy, the combined use of different treatment modalities, better support and increase in survival and quality of $\mathrm{life}^{1-3}$. Nonetheless, children and teenagers with cancer are exposed to the most diverse sort of side effects, especially when submitted to chemotherapy, which despite being one of the most promising means to fight cancer, depending on the chemotherapeutic agents employed it can cause undesirable side effects.

Side effects may manifest themselves earlier on, or in the long run, depending on treatment type and child's age. Hearing loss is among these many side effects ${ }^{4,5}$.

Ototoxicity is defined as a toxic reaction that affects the inner ear, both the auditory and/or the vestibular system and may cause hearing loss ${ }^{6}$. Ototoxicity has taken an important role, especially in younger children, having seen that it is usually irreversible and, thus, it means a loss in the long run ${ }^{7,8}$.

One commonly used classification to assess hearing losses in audiology clinics is the one from Davis and Silverman (1970), mentioned by Russo and Santos (1993) 9 . It is based on determining the degree of hearing loss from air conduction threshold average in the frequencies of 500 , 1000 and $2000 \mathrm{~Hz}$ - the ones most important for speech, considering normal hearing until $25 \mathrm{dBHL}$ (decibel hearing level). However, this classification is the same for adults and children, regardless of the disease, and today we also consider the frequency of $4,000 \mathrm{~Hz}$ as being important.

According to Haggard and Primus (1999) ${ }^{10}$, the scales used to classify hearing loss are not similar, and such fact makes it difficult to compare prevalence. There is much disagreement on which would be the most adequate classification to use for hearing loss, however the consensus is that it is important to adopt a differentiated hearing loss classification for children. According to Northern and Downs (1989) ${ }^{11}$, the ideal tonal threshold for a child is $15 \mathrm{~dB}$ or less in all audiogram frequencies (from 250 to $8000 \mathrm{~Hz}$ ), differently from adults, in which the mean value between $20-25 \mathrm{~dB}$ is acceptable.

In assessing the child's hearing loss, it is important to highlight that even mild loss, which would not impact adults, may interfere in children's capacity to acquire and develop language skills. Hearing loss, even if transitional, between 25 and $35 \mathrm{dBHL}$, this reduction is not enough to prevent the child from hearing, however, it may impair the child's ability to understand some phonema ${ }^{11}$.

In 1991, the American Speech-Language-Hearing Association - ASHA (Hersh and Johnson, 2003) 12 $^{12}$ proposed a hearing loss classification for children. Hearing loss is determined according to the different degrees of difficulty for communication, considering normal hearing the one between 10 and $15 \mathrm{dBHL}$, mild hearing loss between 16 and 25 dBHL, light hearing loss between 26 and 40 dBHL, moderate hearing loss between 41 and $55 \mathrm{dBHL}$, moderately severe hearing loss between 56 and $70 \mathrm{dBHL}$, severe hearing loss between 71 and $90 \mathrm{dBHL}$ and profound hearing loss those above $90 \mathrm{dBHL}$.

In 1994, the American Speech-Language-Hearing Association - ASHA proposed another specific classification for patients treated with ototoxic drugs, the Ototoxicity Criteria (ASHA, 1994) ${ }^{13}$. Such classification classifies hearing loss by means of comparing the results of previous audiologic evaluations, in A (threshold increase in $20 \mathrm{~dB}$ or more in one frequency), B (threshold increase in $10 \mathrm{~dB}$ or more in two sequential frequencies) and $\mathrm{C}$ (no response in three sequential frequencies, which were present in prior audiologic evaluations).

According to Brock et al. (1991) ${ }^{8}$, hearing loss specifically induced by cisplatin has been measured by pre and post treatment audiograms. Notwithstanding, the existing classifications for hearing loss are not adequate to be used in children with cancer, since the most common classifications usually determine the degree of hearing loss based on the mean value of air conduction in the frequencies of 500, 1000 and $2000 \mathrm{~Hz}$ (as the classification from Davis and Silverman, 1970). Thus, the authors proposed an exclusive classification for children treated with cisplatin or other ototoxic drugs. In such classification, hearing loss is classified in levels, according to the frequency that presented tonal threshold below $40 \mathrm{dBHL}$ : Level 0 (hearing thresholds below $40 \mathrm{dBHL}$ in all the frequencies), Level 1 (hearing loss above or equal to 40 dBHL in $8000 \mathrm{~Hz}$ ), Level 2 (Hearing loss above or equal to $40 \mathrm{dBHL}$ in $4000 \mathrm{~Hz}$ and below), Level 3 (hearing loss above or equal to $40 \mathrm{dBHL}$ in $2000 \mathrm{~Hz}$ and below) and Level 4 (hearing loss above or equal to $40 \mathrm{dBHL}$ in 1000 $\mathrm{Hz}$ and in lower frequencies). The classification proposed considers that hearing loss above or equal to $40 \mathrm{dBHL}$, in any frequency, implies loss in speech recognition and, the more it affects speech frequencies, the more harm it brings. The authors consider that after $40 \mathrm{dBHL}$ the hearing loss was surely caused by an external agent, the ototoxic drug in this case - and that in lower intensities, the hearing loss could happen due to other agents.

In 1999, the Pediatric Oncology Group Toxicity - POGT (Huang et al., 2002) ${ }^{14}$ developed a hearing loss classification for children treated with chemotherapeutic agents. This classification also classifies the loss in levels: Level 0 (normal hearing), Level 1 (hearing loss between 20 and $40 \mathrm{dBHL}$ in frequencies above $4000 \mathrm{~Hz}$ ), Level 2 (hearing loss above or equal to $40 \mathrm{dBHL}$ in frequencies above or equal to $4000 \mathrm{~Hz}$ ), Level 3 (hearing loss above or equal to $40 \mathrm{dBHL}$ in frequencies above $2000 \mathrm{~Hz}$ ) and 
Level 4 (hearing loss above or equal to $40 \mathrm{dBHL}$ in 2000 $\mathrm{Hz}$ and below). This classification considers the hearing loss above or equal to $20 \mathrm{dBHL}$ in the frequencies above $4000 \mathrm{~Hz}$ already implies in speech recognition loss and that, the more it affects frequencies between $2000 \mathrm{~Hz}$ and below, the greater is the communication difficulty.

Another classification was proposed by the National Cancer Institute (NCI), the Common Toxicity Criteria version 2.0 (CTC) (1999) $)^{15}$. This classification classifies hearing loss in levels from 0 to 4 , according to the symptoms and the results from the audiologic evaluation: Level 0 (normal hearing), Level 1 (mild hearing loss, no complaints), Level 2 (tinnitus or hearing loss that does not require the use of a hearing aid), Level 3 (tinnitus or hearing loss that requires the use of a hearing aid), Level 4 (severe unilateral or bilateral hearing loss). This classification is subjective - it is based on clinical complaints and on the judgment regarding the relevance or not of using a hearing aid - issues which are difficult to assess, especially in small children.

Recently, another classification was proposed by the National Cancer Institute (NCI), the Common Terminology Criteria for Adverse Events version 3.0 (CTCAEv3) (2003)16. This classification breaks down hearing loss in levels from 1 to 4, by comparing the results of prior audiologic assessments: Level 1 (threshold increase between 15 and $25 \mathrm{~dB}$ in relation to the initial audiologic exam, in two or more sequential frequencies in at least one ear), Level 2 (threshold increase between 25 and $90 \mathrm{~dB}$ in two sequential frequencies), Level 3 (threshold loss greater than or equal to $20 \mathrm{~dB}$ bilaterally in speech frequencies, or greater than or equal to $30 \mathrm{~dB}$ unilaterally) and Level 4 (hearing loss requiring a hearing aid or even a cochlear implant).

Although the classifications proposed by Brock et al. (1991) and by the Pediatric Oncology Group Toxicity (POGT)14 were made in order to assess ototoxicity in specific situations, all of them used the same auditory thresholds in accordance with intensity in different frequencies, which can be used independently from the assessment carried out prior to treatment. In the literature we did not find any study that compared and discussed the relevance of using these classifications. Having said that, the goals of the present investigations are to determine hearing loss prevalence among children and teenagers with cancer using the classifications from the American Speech-Language-Hearing Association (ASHA), of Bilateral Hearing Loss (BHL) and from the Pediatric Oncology Group Toxicity (POGT), and check the agreement of these three classifications in the diagnosis of hearing loss.

\section{MATERIALS AND METHODS}

The present investigation was developed in an institute which is the national reference center for the treatment of pediatric cancer, and was approved by the Research Ethics Committee of the School of Public Health of the University of São Paulo, under protocol \# 1186 and the Ethics Committee for the Analysis of Research Projects - CAPPesq of the University of São Paulo Hospital Executive Board, protocol \# 104/06.

After surveying patients' charts, we noticed that 325 new cases were seen in 2003; and 342 in 2004; most of them, 469 children $(=70.3 \%)$, did not have the diagnosis of cancer confirmed and were referred to another unit for specific treatment.

Therefore, we selected 87 new cases seen in 2003 and 111 new cases seen in 2004 for our investigation, making up a total of 198 patients. Of these, 44 (22.2\%) died and 12 (6.1\%) were transferred to other treatment centers located in other cities/capitals, leaving a total of 142 patients. Since pre-treatment audiologic evaluation is not carried out routinely in this institute, these patients were not included in this study.

We first assessed the medical chart of these patients in order to fill out the form and, later we scheduled their audiologic exam.

Among the 142 patients, we were able to do the audiologic exam in 94 patients.

\section{The audiologic exam}

We first carried out an anamnesis in order to look for any symptom or hearing loss complaint. Later on, we visually inspected the external acoustic meatus with an otoscope, checking for wax or any other thing that could prevent these exams. If a wax ball was seen, the patient was then referred to the otorhinolaryngologist to remove it, and only afterwards the exam was carried out.

Following that, auditory thresholds were evaluated, by means of conditioned response methods (audiometry with visual reinforcement - children of up to two years of age; conditioned audiometry within a ludic activity - children between 2 and 5 years; or tonal threshold audiometry - children above 5 years, with the aim of determining their hearing thresholds. This test was carried out in an acoustic booth, using the Maico MA-41 audiometer with TDH-39 phones, duly calibrated according to current standards, in the frequencies of 250 to $8000 \mathrm{~Hz}$ and, by bone conduction, in the frequencies of 500 to $4000 \mathrm{~Hz}$, whenever necessary in order to confirm the findings. Later on, we carried out tympanometry and acoustic reflexes test using the Danplex ZA-28 impedance meter device. All the tests were carried out by the same audiologist (AMS).

In order to define the hearing loss, three classifications were used: American Speech-Language-Hearing Association (ASHA), Bilateral Hearing Loss (BHL) and the Pediatric Oncology Group Toxicity (POGT).

The sample was characterized by means of descriptive statistics (mean, standard deviation, median and pro- 
portions) and we analyzed the three classifications insofar as their agreement is concerned in terms of hearing loss by means of the Kappa statistics. In all statistical analysis we used the $5 \%$ level of statistical significance.

We used the Epi Info v. 6.04 for DOS software for database double entry and data consistence; and the SPSS v. 12.0 for Windows for statistical analyses.

The audiologic evaluation did not involve any invasive procedure and all parents and guardians signed the informed consent. At the end of the exam, we handed the results of this audiologic evaluation to the children's parents or guardians.

\section{RESULTS}

There were more males in the sample (52.1\%) than females. Caucasians were also more common (83.0\%), followed by browns (11.7\%). Age at diagnosis varied between 0 and 18 years (mean of 6.8 years; standard deviation of 4.9 years; median of 5.6 years), and less than half of the patients were diagnosed before 5 years of age (45.7\%). Current age varied between 1 and 18 years (mean age of 8.6 years; standard deviation of 4.8 years; median of 7.4 years) and the most frequently found age range was between 5 and 9 years (38.3\%), followed by that of

Table 1. Number and percentage of patients, according to topography and the use of cisplatin and/or ifosfamide.

\begin{tabular}{lcc}
\hline Topography & $\#$ & $\%$ \\
\hline Lymphoid leukemia & 29 & 30.8 \\
Bone tumors (osteossarcoma, Ewing's sarcoma) & 8 & 8.5 \\
Willms's tumor & 8 & 8.5 \\
Retinoblastoma & 7 & 7.4 \\
Neuroblastoma & 6 & 6.3 \\
Meduloblastoma & 5 & 5.3 \\
Adrenal carcinoma & 5 & 5.3 \\
Nasopharyngeal carcinoma & 4 & 4.3 \\
Hepatoblastoma & 4 & 4.3 \\
Soft tissue sarcomas (rabdomyossarcoma, fuso- & 4 & 4.3 \\
cellular) & & \\
Non-lymphoid acute leukemia & 4 & 4.3 \\
Hodgkin's lymphoma & 2 & 2.1 \\
Malignant histiocytosis & 2 & 2.1 \\
Stem cells tumor & 2 & 2.1 \\
CNS tumor (glioblastoma multiforme) & 1 & 1.1 \\
Non-Hodgkin lymphoma & 1 & 1.1 \\
Thyroid carcinoma & 1 & 1.1 \\
Peripheral neuroectodermal tumor & 1 & 1.1 \\
\hline Total & 94 & 100.0 \\
\hline
\end{tabular}

*(used by one patient who relapsed)
10 years and above (36.2\%).

The most frequent diagnosis was of lymphoid leukemia (30.8\%), followed by the bone tumors group (8.5\%) and Willms's tumor (8.5\%) (Table 1). Patients diagnosed with lymphoid leukemia, bone tumors, neuroblastoma, meduloblastoma, adrenal carcinoma, nasopharyngeal carcinoma, hepatoblastoma, soft tissue sarcoma, Hodgkin lymphoma, female-germ cells' tumor, male-germ cells' tumor and peripheral neuroectodermal tumor patients used cisplatin and/or ifosfamide. Patients diagnosed with Willms's tumor, retinoblastoma, non-lymphoid acute leukemia, malignant histiocytosis, CNS tumor, non-Hodgkin lymphoma and thyroid carcinoma did not use these drugs.

Of the 94 patients, 38 (40.4\%) had pain in their bodies at the time of diagnosis, followed by fever (34.0\%) and increase in body mass volume (31.9\%). The less frequent symptom was motor change (3.2\%), mentioned only by

Table 2. Number and percentage of patients according to drug used.

\begin{tabular}{|c|c|c|}
\hline Drug & $\#$ & $\% *$ \\
\hline Folinic acid & 31 & 33.0 \\
\hline Dactinomycin & 18 & 19.1 \\
\hline Adriamycin & 39 & 41.5 \\
\hline Arabinosil Citosine (high dose) & 15 & 16.0 \\
\hline Arabinosil Citosine (low dose) & 33 & 35.1 \\
\hline L-Asparaginase (U) & 26 & 27.7 \\
\hline Carboplatin & 21 & 22.3 \\
\hline Cyclophosphamide & 46 & 48.9 \\
\hline Cisplatin & 21 & 22.3 \\
\hline Daunorubicin & 27 & 28.7 \\
\hline Dexametasone & 35 & 37.2 \\
\hline Etoposide & 42 & 44.7 \\
\hline 5-Fluorouracil & 7 & 7.4 \\
\hline Ifosfamide & 20 & 21.3 \\
\hline 6-Mercaptopurin & 32 & 34.0 \\
\hline Metotrexate (high dose) & 34 & 36.2 \\
\hline Metotrexate (low dose) & 35 & 37.2 \\
\hline Prednisone & 5 & 5.3 \\
\hline Teniposide & 11 & 11.7 \\
\hline Topotecan & 6 & 6.4 \\
\hline Vancomycin & 6 & 6.4 \\
\hline Vinblastine & 4 & 4.3 \\
\hline Vincristine & 55 & 58.5 \\
\hline Metotrexate (MADIT) & 29 & 30.9 \\
\hline AraC (MADIT) & 29 & 30.9 \\
\hline Dexametasone (MADIT) & 24 & 25.5 \\
\hline
\end{tabular}

* Percentage calculated in relation to the 94 patients. 
three patients.

Among the 94 patients, 67 (71.3\%) were alive without chemical or radiotherapy treatment at the time of the last visit recorded in their medical charts; and 27 (28.7\%) were alive and under treatment.

Table 2 describes the use of medication with these patients. 21 patients (22.3\%) used Cisplatin - considered highly ototoxic, at a mean individual dose of $78.09 \mathrm{mg} / \mathrm{m}^{2}$ (standard deviation $=32.69 \mathrm{mg} / \mathrm{m}^{2}$ ), maximum individual dose of $140 \mathrm{mg} / \mathrm{m}^{2}$, maximum cumulative dose of 1120 $\mathrm{mg} / \mathrm{m}^{2}$ and average number of treatment cycles of 4.24 ( standard deviation $=1.55$ cycles $)$.

21 patients (22.3\%) received carboplatin, cisplatinanalogue drug, however of lower ototoxic potential, at a mean individual dose of $330.75 \mathrm{mg} / \mathrm{m}^{2}$ (standard deviation $\left.=208.21 \mathrm{mg} / \mathrm{m}^{2}\right)$, maximum individual dose of 775 $\mathrm{mg} / \mathrm{m}^{2}$, maximum cumulative dose of $4500 \mathrm{mg} / \mathrm{m}^{2}$ and number of cycles mean value of 4.14 (standard deviation $=2.82$ cycles) .

Most commonly mentioned hearing complaint was otitis (22.3\%), followed by otalgia (16.0\%), dizziness (16.0\%), hearing difficulties (14.9\%) and upper airway infections (13.8\%).

Table 3 shows the hearing loss classification according to the three different classifications. We see that according to the ASHA's classification, 54 (57.5\%) patients had hearing thresholds within normal limits and 40 (42.5\%) had some degree of hearing loss. Considering BHL, 82

Table 3. Number and percentage of patients according to hearing loss classification.

\begin{tabular}{|c|c|c|c|}
\hline Classification & Category & № & $\%$ \\
\hline \multirow{6}{*}{ ASHA } & Normal & 54 & 57,5 \\
\hline & Mild loss & 16 & 17,0 \\
\hline & Light loss & 14 & 14,9 \\
\hline & Moderate loss & 2 & 2,1 \\
\hline & Moderately severe loss & 7 & 7,4 \\
\hline & Severe loss & 1 & 1,1 \\
\hline \multirow{5}{*}{ BHL } & Level 0 & 82 & 87,2 \\
\hline & Level 1 & 5 & 5,3 \\
\hline & Level 2 & 2 & 2,1 \\
\hline & Level 3 & 4 & 4,3 \\
\hline & Level 4 & 1 & 1,1 \\
\hline \multirow{6}{*}{ POGT } & Level 0 & 56 & 59,6 \\
\hline & Level 1 & 29 & 30,8 \\
\hline & Level 2 & 3 & 3,2 \\
\hline & Level 3 & 5 & 5,3 \\
\hline & Level 4 & 1 & 1,1 \\
\hline & TOTAL & 94 & 100,0 \\
\hline
\end{tabular}

Table 4. Number and percentage of patients according to the agreement between classification methods BHL and POGT.

\begin{tabular}{|c|c|c|c|c|c|c|}
\hline \multirow{3}{*}{$\mathrm{BHL}$} & \multicolumn{4}{|c|}{ POGT } & & \\
\hline & \multicolumn{2}{|c|}{ Level 0} & \multicolumn{2}{|c|}{$\begin{array}{l}\text { Levels } 1 \\
\text { through } 4\end{array}$} & \multicolumn{2}{|c|}{ Total } \\
\hline & № & $\%$ & № & $\%$ & № & $\%$ \\
\hline Level 0 & 56 & 100,0 & 26 & 68,4 & 82 & 87,2 \\
\hline $\begin{array}{c}\text { Levels } \\
1 \text { a } 4 \\
\end{array}$ & -- & -- & 12 & 31,6 & 12 & 12,8 \\
\hline TOTAL & 56 & 100,0 & 38 & 100,0 & 94 & 100,0 \\
\hline
\end{tabular}

Kappa $=0,36(p<0,001)$

Table 5. Number and percentage of patients according to the agreement between classification methods $\mathrm{BHL}$ and ASHA.

\begin{tabular}{ccccccc}
\hline \multirow{2}{*}{ BHL } & \multicolumn{2}{c}{ Normal } & \multicolumn{2}{c}{ Loss } & \multicolumn{2}{c}{ Total } \\
& № & $\%$ & № & $\%$ & № & $\%$ \\
\hline Level 0 & 54 & 100,0 & 28 & 70,0 & 82 & 87,2 \\
$\begin{array}{c}\text { Levels 1 } \\
\text { through 4 }\end{array}$ & -- & -- & 12 & 30,0 & 12 & 12,8 \\
\hline TOTAL & 54 & 100,0 & 40 & 100,0 & 94 & 100,0 \\
\hline
\end{tabular}

Kappa $=0,33(p<0,001)$

Table 6. Number and percentage of patients according to the agreement between classification methods POGT and ASHA.

\begin{tabular}{ccccccc}
\hline \multirow{2}{*}{ BHL } & \multicolumn{2}{c}{ Normal } & \multicolumn{2}{c}{ Loss } & \multicolumn{2}{c}{ Total } \\
& № & $\%$ & № & $\%$ & № & $\%$ \\
\hline Level 0 & 54 & 100,0 & 2 & 5,0 & 56 & 59,6 \\
$\begin{array}{c}\text { Levels 1 } \\
\text { through 4 }\end{array}$ & -- & -- & 38 & 95,0 & 38 & 40,4 \\
\hline TOTAL & 54 & 100,0 & 40 & 100,0 & 94 & 100,0 \\
\hline
\end{tabular}

Kappa $=0,96(p<0,001)$

(87.2\%) patients had hearing thresholds classified in Level 0 and $12(12.8 \%)$ patients with some degree of hearing loss. And finally, considering POGT's classification, only 56 (59.6\%) patients under levels 0 and 38 (40.4\%) had some degree of hearing loss, in other words, result very similar to the one found by using the ASHA classification.

The agreement in the hearing loss diagnosis according to classifications POGT and PAB was weak (Kappa = 0.36; $\mathrm{p}<0.001$; Table 4), and the same thing happened for BHL in relation to ASHA's (Kappa $=0.33 ; \mathrm{p}<0.001$; Table 5). The agreement between ASHA and POGT was almost perfect $($ Kappa $=0.96 ; \mathrm{p}<0.001$; Table 6). 


\section{DISCUSSION}

One of the first things to be highlighted is the hearing evaluation itself is that the institute where this study was conducted does not have a department of audiology, and is also not specialized in speech and hearing therapy. This is not a particularity of this institute, having seen that in Brazil pediatric cancer treatment centers still do not have a common practice of monitoring patients' hearing. Thus, we recommend that cancer treatment authorities should be concerned in installing audiology services in cancer treatment centers in order to follow these children and teenagers with cancer and also those with other diseases that may have their hearing compromised by treatment.

In the hearing loss prevalence analysis by the ASHA classification, we found $42.5 \%$ of the patients with mild to severe hearing loss. In the literature we did not find any study that used the ASHA classification. It is important to stress that this classification is the strictest among the classifications adopted. Patients who had hearing threshold above $15 \mathrm{dBHL}$ in any frequency were analyzed as having hearing loss. This classification was very much in agreement with the POGT classification (Kappa=0.96), and the only difference was that two patients were classified as Level 0 by POGT, but were considered as having mild loss in frequencies below $4000 \mathrm{~Hz}$ by the ASHA classification.

The major agreement in the hearing loss diagnosis between ASHA's and POGT's classification happened thanks to the threshold used as cutting point to determine the hearing loss (15 dBHL for ASHA and 20 dBHL for POGT).

When the POGT's classification was used to classify hearing losses, $40.4 \%$ of the patients evaluated had hearing loss between levels 1 and 4 . Among the studies that used this classification, the one from Marina et al. (2005)17 with 24 patients with germ cells tumors, treated with cisplatin, found $75 \%$ of patients with hearing loss between levels 2 and 4. In the study developed by Ruiz et al. (1989)18, the researchers used the threshold above or equal to 20 dBHL to classify the hearing loss, and 100\% of their patients treated with cisplatin had hearing loss.

In the BHL, only those thresholds above or equal to $40 \mathrm{dBHL}$ are classified as hearing loss. Thus, the number of patients with hearing loss using this classification is much lower when compared to the other two. The agreement between the BHL and the ASHA classifications was weak (Kappa $=0.33$ ), and the same happened with the POGT classification (Kappa $=0.36$ ).

When we used the BHL classification, $12.8 \%$ of the patients evaluated had hearing loss between levels 1 and 4 . Since this classification only considers hearing loss above $40 \mathrm{dBHL}$, the mild or light hearing loss in the ASHA classification is classified as Level 0 in the BHL.

In Skinner et al.'s study (1990)7 involving 22 chil- dren and adolescents diagnosed with solid tumors and treated with cisplatin, $73 \%$ had hearing loss. Brock et al. (1991)8 found hearing loss in $48 \%$ of the 29 children with different diagnoses, treated with cisplatin.

Other studies adopted a threshold equal to or above $25 \mathrm{dBHL}$ in any frequency, between 250 and $8000 \mathrm{~Hz}$ as a means of hearing loss classification. The percentage of loss varied between $43 \%$ and $81 \% \%^{2,19-21}$.

Allen et al. (1998)20 carried out a retrospective study with 11 children below 18 years of age who received cisplatin during chemotherapy between 1985 and 1994. They found hearing loss between 25 and $90 \mathrm{dBHL}$ in $81 \%$ of the children. We found similar figures in the present investigation (83\%), when compared to the POGT classification (the closest one for the cutting point at $25 \mathrm{dBHL}$ ).

Another means to analyze and classify hearing loss was by comparing the hearing thresholds of the audiologic evaluations before and after treatment. Studies which adopted an increase in the threshold in any frequency equal to or greater than $10 \mathrm{dBHL}$ when compared to the previous audiologic evaluation, found between $77 \%$ and $88 \%$ of hearing loss in the patients evaluated ${ }^{22,23}$. In the study carried out by Berg et al. (1999) ${ }^{24}$, hearing loss happened to only $26 \%$ of the children assessed.

Other studies did not report on which was the classification used to classify hearing loss, and hearing loss rate varied between $7 \%$ and $42 \%^{25-27}$.

Therefore, we see that comparing hearing loss in children and teenagers with cancer is very difficult - above all - by the use of more or less strict criteria to assess hearing.

Smits et al. (2006) ${ }^{28}$ stressed that hearing loss, even when mild, if not detected early on may cause problems in the long run. Hearing loss diagnoses in patients being treated for cancer is of paramount importance; since it may preserve their communications capacity and avoid that when they recover from cancer they may have hearing sequelae because of their prior treatment ${ }^{29}$.

We must highlight that using more strict criteria, such as the one proposed by the American Speech-Language-Hearing Association - ASHA, for hearing loss in children is fundamental, because in order to communicate well, the child must be able to hear, identify and discriminate all speech-related sounds. A reduction in hearing, even if mild, compromises the development of such skills, impairing understanding and thus, oral communication, it may cause emotional, behavioral and educational problems.

\section{REFERENCES}

1. Garrè ML, Gandus S, Cesana B, Haupt R, De Bernardi B, Comelli A, et al. Health status of long-term survivors after cancer in childhood. Am J Pediatr Hematol Oncol 1994;16(2):143-52.

2. Ilveskoski I, Saarinen UM, Wiklund T, Perkkiö M, Salmi TT, Lanning $\mathrm{M}$, et al. Ototoxicity in children with malignant brain tumors treated with the " 8 in 1 " chemotherapy protocol. Med Pediatr Oncol 
1996;27:26-31.

3. Mirra AP, Latorre MRDO, Veneziano DB. Incidência, mortalidade e sobrevida do câncer da infância no município de São Paulo. Registro de Câncer de São Paulo; 2004. p.1-3

4.Camargo B, Lopes LF, Novaes PE. O tratamento multidisciplinar das neoplasias na infância. In: Camargo B, Lopes LF, organizadores. Pediatria oncológica: noções fundamentais para o pediatra. São Paulo: Lemar; 2000. p.215-29.

5. Lopes LF, Camargo B, Bianchi A. Os efeitos tardios do tratamento do câncer infantil. Rev Ass Med Brasil 2000;46(3):277-84

6. Oliveira JAA. Ototoxicidade. In: Costa SS, Cruz OLM, Oliveira JAA, organizadores. Otorrinolaringologia. Porto Alegre: Artes Médicas Sul; 1994. p. 215-21.

7. Skinner R, Pearson ADJ, Amineddine HA, Mathias DB, Craft AW. Ototoxicity of cisplatinum in children and adolescents. Br J Cancer 1990;61:927-31.

8. Brock PR, Bellman SC, Yeomans EC, Pinkerton CR, Pritchard J. Cisplatin ototoxicity in children: a practical grading system. Med Pediatr Oncol 1991;19:295-300.

9. Russo ICP, Santos TMM. Caracterização audiológica das principais patologias do ouvido. In: Russo ICP, Santos TMM. A Prática da Audiologia Clínica. São Paulo: Cortez; 1993. p.213-53.

10. Haggard RS, Primus MA. Parental perceptions of hearing loss classification in children. Am J Audiol 1999;8:1-10.

11. Northern JL, Downs MP. Audição em crianças. São Paulo: Manole; 1989.

12. Hersh MA, Johnson MA. Anatomy and physiology of hearing, hearing impairment and treatment. In: Hersh MA, Johnson MA, organizadores. Assistive technology for the hearing-impaired, deaf and deafblind. London: Springer; 2003.p.1-39.

13. American Speech-Language-Hearing Association. Guidelines for the audiologic management of individuals receiving cochleotoxic drug therapy. ASHA. 1994;36(12):11-9.

14. Huang E, Teh BS, Strother DR. intensity-modulated radiation therapy for pediatric medulloblastoma: early report on the reduction of ototoxicity. Int J Radiat Oncol Biol Phys 2002;52(3):599-605.

15. Common toxicity criteria version 2.0 - CTC; 1999. DCTD, NCI, NIH, DHHS [Site na internet]. Disponível em: http://ctep.cancer.gov. Acessado em 23 de agosto de 2005.

16. Common terminology criteria for adverse events version 3.0 - CTCAE; 2003. DCTD, NCI, NIH, DHHS [Site na internet]. Disponível em: http://ctep.cancer.gov. Acessado em 12 de dezembro de 2005.
17. Marina N, Chang KW, Malogolowkin M, London WB, Frazier AL, Womer RB et al. Amifostine does not protect against the ototoxicity of high-dose cisplatin combined with etoposide and bleomycin in pediatric germ-cell tumors. Cancer 2005;104(4):841-47.

18. Ruiz L, Gilden J, Jaffe N, Robertson R, Wang YM. Auditory function in pediatric osteosarcoma patients treated with multiple doses of cis-diamminedichloroplatinum (II). Cancer Res 1989;49:742-44.

19. Kretschmar CS, Warren MP, Lavally BL, Dyer S, Tarbell N. Ototoxicity of preradiation cisplatin for children with central nervous system tumors. J Clin Oncol 1990;8(7):1191-98.

20. Allen GC, Tiu C, Koike K, Ritchey K, Kurs-Lasky M, Wax MK Transient-evoked otoacoustic emissions in children after cisplatin chemotherapy. Otolaryngol Head Neck Surg 1998;1118(5):584-88.

21. Garcia AP, Iório MCM, Petrilli AS. Monitoramento da audição de pacientes expostos à cisplatina. Rev Bras Otorrinolaringol 2003;69(2):215-21.

22. McHaney VA, Thibadoux G, Hayes FA, Green AA. Hearing loss in children receiving cisplatin chemotherapy. J Pediatr 1983;102(2):31417.

23. Pasic TR, Dobie RA. Cis-platinum ototoxicity in children. Laryngoscope 1991;101:985-91.

24. Berg AL, Spitzer JB, Garvin Junior JH. Ototoxic impact of cisplatin in pediatric oncology patients. Laryngoscope 1999;109:1806-14.

25. Fromm M, Littman P, Raney B, Nelson L, Handler S, Diamond G et al. Late effects after treatment of twenty children with soft tissue sarcomas of the head and neck: experience at a single institution with a review of the literature. Cancer 1986;57:2070-76.

26. Paulino AC, Simon JH, Zhen W, Wen BC. Long-term effects in children treated with radiotherapy for head and neck rhabdomyosarcoma. Int J Radiat Oncol Biol Phys 2000;48(5):1489-95.

27. Skowronska-Gardas A, Pedziwiatr K, Choinacka M. Evaluation of quality of life in long-term survivors of paediatric brain stem tumors, treated with radiotherapy. Radiother Oncol 2004;70:269-73.

28. Smits C, Swen SJ, Goverts ST, Moll AC, Imhof SM, Meeteren AYNS Assessment of hearing in very young children receiving carboplatin for retinoblastoma. Eur J Cancer 2006; $42: 492-500$.

29. Pedalini MEB, Toniosso S, Goffi MVS. O papel do audiologista no tratamento do paciente com câncer. In: Barros APB, Arakawa L, Tonini MD, Carvalho VA, organizadoras. Fonoaudiologia em Cancerologia. São Paulo: Fundação Oncocentro de São Paulo; 2000. p.105-9. 